\title{
HOW UNIVERSAL IS HAPPINESS?
}

\author{
Ruut Veenhoven \\ Chapter 11 in Ed Diener, John F. Helliwell \& Daniel Kahneman (Eds.) International \\ Differences in Well-Being, 2010, Oxford University Press, New York, ISBN-13: 978-0-19- \\ 973273-9
}

\begin{abstract}
There is a longstanding discussion on whether happiness is culturally relative or not. The following questions are addressed in that context:

1) Do we all assess how much we like our life?

2) Do we appraise our life on the same grounds?

3) Are the conditions for happiness similar for all of us?

4) Are the consequences of happiness similar in all cultures?

5) Do we all seek happiness?

6) Do we seek happiness in similar ways?

7) Do we enjoy life about equally much?

The available data suggest that all humans tend to assess how much they like their life. The evaluation draws on affective experience, which is linked to gratification of universal human needs and on cognitive comparison which is framed by cultural standards of the good life. The overall appraisal seems to depend more on the former, than on the latter source of information. Conditions for happiness appear to be quite similar across the world and so are the consequences of enjoying life or not. There is more cultural variation in the valuation of happiness and in beliefs about conditions for happiness. The greatest variation is found in how happy people are.
\end{abstract}

Key words: happiness, life satisfaction, cultural relativism, human nature, utilitarianism

\section{INTRODUCTION}

The recent rise of interest in happiness has revived classic discussions about the nature of happiness. One of these discussions centers on whether happiness is similar for all humans or rather something that varies across cultures. In the universalist view, happiness is comparable to "pain." All humans know what pain is, will experience pain when touching a hot stove, and tend to avoid pain. In the relativistic view, happiness is more comparable to "beauty,” the idea of which varies across time and culture. Picasso's paintings are not appreciated by everybody, nor does everybody seek only beauty ${ }^{1}$.

This discussion links up with wider issues, among which is the longstanding debate about the merits of utilitarian moral philosophy. Its "greatest happiness principle” assumes that happiness is something universal. If different in different cultures, happiness cannot serve for the evaluation of cultures. If culturally variable, the definition of happiness can also 
change over time, and happiness is therefore not a strong criterion for public choice within cultures. These arguments have been presented repeatedly, with few conclusions arising from the discussions, due to a lack of empirical proof for either position.

In this chapter, I inspect what our new knowledge about happiness can tell us about this old controversy. Has a decade of empirical research made us any wiser on this matter, or are we still as much in the dark as the nineteenth-century armchair philosophers who criticized utilitarianism on this ground?

\subsection{Concept of happiness}

A preliminary step is to define happiness, since some of the things denoted using this word can be less universal than others things called by the same name. I use the word "happiness" for a subjective state of mind, which I define as the overall appreciation of one's life as -a whole. I have elaborated this definition in earlier publications (Veenhoven, 1984 chapter 2; Veenhoven, 2000). This definition fits Jeremy Bentham's classic notion of happiness as "the sum of pleasures and pains." Happiness in this sense is synonymous with "life satisfaction" and "subjective well-being" 2 .

Additionally, I distinguish two “components” of happiness: an affective component and a cognitive component. The affective component is how well one typically feels. I call this the hedonic level of affect. The cognitive component is the perceived difference between what one has and what one wants in life, which I call contentment. I assume that these components serve as subtotals in the overall evaluation of life.

\subsection{Sub-questions}

The question “How universal is happiness?” is too broad to answer, since there are different facets of happiness, which may be more or less universal. Hence I will break down the main question into the following sub-questions:

1) Do we all appraise how much we like life?

2) Do we appraise life on the same grounds?

3) Are the conditions for happiness similar for all humans?

4) Are the consequences of happiness similar around the globe?

5) Do we all seek happiness?

6) Do we seek happiness in similar ways?

7) Are we about equally happy in all cultures?

Since the focus of this chapter is on cultural variations in the nature of happiness, I do not deal with the cross-cultural measurement of happiness. Cultural measurement bias may distort the data on which this chapter builds in several ways, but the literature suggests that the degree of distortion is not alarming (see, e.g., Diener \& Oishi, 2004; Veenhoven, 2008c). Some issues in cross-cultural measurement of happiness are discussed in the chapter by Oishi (2009) in this volume. 


\subsection{Data source}

Most of the empirical data used in this chapter are taken from the World Database of Happiness (Veenhoven, 2008), which is a collection of research findings on happiness as defined above. References are made to sections of this database. In each of these sections one can find standardized descriptions of research findings and links to the original publication. Citing these all separately would be unwieldy.

\section{Question 1:}

\section{DO WE ALL APPRAISE HOW MUCH WE LIKE LIFE?}

Above, I distinguished between overall happiness and its components and assumed that the components serve as subtotals in the overall evaluation of life. Do all humans appraise their life in these ways?

\subsection{Hedonic level of affect}

Like other higher animals, humans experience positive and negative affects. This is not just something we know from our own experience, it is also something we can recognize in the facial expressions of other people all over the world (Ekman, 1970). Using brain imaging we can now also observe part of the neural processes that make us feel so (e.g., Davidson, 2004) and these neurological structures do not differ across cultures either ${ }^{3}$.

The balance of positive and negative affects is reflected in the hedonic tone of "mood." Though mood is something we are aware of, it is mostly not in the foreground of our consciousness. Still, it is assessable, and we can estimate how well we feel most of the time. Babies are not yet able to engage in such reflection, but they still experience happy or unhappy moods. Although they cannot report how they typically feel, their mood level can be assessed using behavioral indications. This case of babies illustrates that one can be happy without having a concept of happiness in mind.

Adult humans know typically how well they feel most of the time and this appears in the practice of measurement. When asked how well they usually feel, people answer instantly. The non-response rate tends to be small. Self-ratings of average hedonic level do not differ much from the balance scores scientists compute from responses to multiple questions about specific affects ${ }^{4}$ and do not differ substantially from ratings based on experience sampling ${ }^{5}$ or from ratings by intimates ${ }^{6}$.

\subsection{Contentment}

Unlike their fellow animals, humans can develop ideas of what they want from life and then compare these aspirations with the realities of their life. This faculty is not present from birth on, but develops on the road to adulthood. There is no doubt that all adults have wants, even ascetics who want to denounce all wants still have the desire to denounce wants. There is also no doubt that most adults have an idea of how well their wants are being met, at least about important wants. Wants are often not very specific, and few people have clear priorities in 
mind; nevertheless, most people have no problem in estimating of how successful they are in getting what they want from life.

Several survey studies have involved questions about what one wants from life and the degree to which one sees these wants being met. A common question is: "So far, I have gotten the important things I want in life” (item in Diener's "Satisfaction with Life Scale," Diener et al., 1985). The responses tend to be prompt, and the percentage of respondents who use the "Don't know" option is very low. So, apparently, this question links up with something people have in mind.

Even if people have no overall judgment of success already in mind, they appear able and willing to make one when asked. This appears in the practice of focused interviews, in life-review interviews in particular. Like in the case of hedonic level it is not required that people have made up their mind: an external observer can estimate someone's overall contentment based on that person's reported success in meeting specific wants.

\subsection{Overall happiness}

Given the above, it is no surprise that people have no problem in reporting how much they like their life-as-a-whole. Responses to questions on overall happiness are typically prompt. If not, happiness would not be such a common item in survey research. The non-response level to questions on happiness is typically low. Fewer than 1 percent use the "Don't know" option $^{7}$, and few people skip the question ${ }^{8}$. (See Scheme 1.) Non-response is much higher on questions about other issues such as income and political preference. Questions on lifesatisfaction are also easily answered in non-modern societies, such as the Inughuit, the Amish, and the Maasai (Biswas-Diener et al., 2005).

\section{Question 2:}

\section{DO WE APPRAISE LIFE ON THE SAME GROUNDS?}

As mentioned above, I assume that we appraise our life in two ways: affectively, by assessing how well we feel; and cognitively, by comparing life-as-it-is with how we want-life-to-be. This theory is summarized in Scheme 2.

\subsection{Hedonic level depends on gratification of universal "needs"}

Why can we experience pleasure and pain? The biological function is evidently to signal that things are good or bad for us. Evolution has programmed us this way. What, then, is the function of mood? Clearly not to signal specific benefit or danger: unlike pleasure and pain, moods are typically not related to specific stimuli and certainly not average mood level over longer periods of time. Mood level seems to function as a meta-signal and indicates how well we are doing on the whole. Feeling good means that all lights are on green and that we can go ahead, while feeling bad means that there is something wrong and that we should check what 
that is. This affective signal mechanism seems to exist in all higher animals, and its neural basis is found in the evolutionarily eldest parts of the human brain.

What, then, is "doing well"? I assume, but cannot prove, that this is meeting innate "needs." Needs are requirements for functioning that are so essential that evolution has safeguarded their gratification by linking these functions to affective signals. This is pretty evident in the case if "deficiency needs" such as hunger, but it seems also to apply to "growth needs" such as curiosity ${ }^{9}$.

In this view, happiness is rooted in the gratification of basic needs that are part of human nature. In that respect happiness draws on universal grounds. I have discussed this theory in more detail elsewhere (Veenhoven, 1991, 2009).

\subsection{Contentment depends on meeting culturally variable "wants"}

Why do we have wants? Mainly to gratify universal needs. In lower animals, needs are met by means of instinctive behaviors. The human strategy is more flexible than that and allows need gratification though planned behavior. "Wants" are a part of that planning.

What do we want? Part of the answer is that we tend to adopt current standards of the good life; e.g., the standard of what material level of living is desirable and possible. These standards vary across time and culture; today we want more material comfort than our greatgrandparents could dream of, and standards are higher in American business circles than in Tibetan monasteries.

In this view, happiness is rooted in social standards and in this respect is culturally relative. For a recent statement of this view, see Chambers (1999).

\subsection{Affective experience dominates in the overall evaluation of life}

In this line of thought, the question of how universal "happiness" is boils down to the question which of these two ways of appraising life is the most important. I have considered this question in earlier publications (Veenhoven, 1991, 2009) and concluded that affective experience dominates the overall evaluation of life. Below I will summarize the main arguments and present some more evidence.

\subsubsection{Theoretical plausibility}

From an evolutionary point of view it is not plausible that cognitive contentment dominates our overall appraisal of life. Cognition developed much later and serves as an addition to affective appraisal rather than a substitute. Reason helps explain why we feel good or bad and allows detection of false affective signals, although it is difficult to ignore these, as depressives can tell you. Affective appraisal tends to precede cognitive decision (Zajonc, 1984), and without affective appraisal we cannot come to a decision, as cases of brain damage demonstrate (Damasio, 1994). From this perspective it is also unlikely that humans orient by variable cultural standards in the first place, rather than by needs that are rooted in biological evolution $^{10}$.

The limited role of cognitive comparison is also illustrated by the fact that it does not exist in little children, who as yet have no idea of what they want from life. Still, it is clear 
that children can be happy or unhappy, and there is typically no great change in happiness when they develop wants.

\subsubsection{Empirical indications}

Since we cannot (yet) look into people's heads, there is no direct empirical evidence of the relative strength of both ways of appraising life. Still, there are several indirect indications.

\section{Overall happiness more correlated to affect than contentment:}

If affective experience dominates the overall appraisal of life, this must appear in sizable correlations with overall happiness and more sizable correlations than with contentment. Unfortunately, there are no reports of studies involving measures of all three of these variants of happiness, so we must make do with studies that correlated either happiness with affect or overall happiness with contentment. The findings of such studies are stored in the World Database of Happiness, which distinguishes measures of overall happiness (coded "O"), measures of affect level (coded “ $A$ ”) and measures of contentment (coded " $C$ ”).

Eight studies link self-ratings of overall happiness and average affect and find an average correlation of $+.70^{11}$. Another 13 studies relate responses to global questions on overall happiness and contentment and find an average correlation of $+.46^{12}$. Not surprisingly, the correlation between hedonic level and contentment is weaker. The average in three studies is $+.40^{13}$. An even lower correlation was observed in the recent Gallup World Poll, the correlation between Best-Worst possible life and Yesterday's Affect being around +.20 (Harter \& Arora, 2009).

\section{Happy with unfulfilled aspirations:}

If happiness depends on seeing one's wants met, people must be unhappy when they have unfulfilled aspirations and increasingly unhappy the more unfulfilled aspirations they have. Yet people with unfulfilled aspirations appear to be happier than people without, and more so the more unfulfilled aspirations they have (Wessman, 1965, p. 210) ${ }^{14}$. This finding fits better with the theory that we have an innate need to use our potentials, since unfulfilled aspirations provide an aim to achieve.

\section{Happy in spite of value-reality gap in nation:}

If contentment drives happiness in the first place, we can expect that people are happier in nations where the values endorsed are perceived to be met than in nations where a gap between value and reality is perceived to exist. This is not always the case; for instance, not with "gender equality" and "human orientation" as measured in the Globe study in 62 societies (House et al., 2004). Average happiness is higher in nations where the widest gaps between ideal and reality are perceived to exist on these issues, probably because this marks respect for humanistic values. 
Happiness drives contentment rather than the reverse:

The right arrow in Scheme.2 denotes a "bottom-up" effect of contentment on overall happiness. Above, I have interpreted the observed correlations in this way. Yet causality can also be "top-down," overall happiness affecting the perception of the gap between what one wants and what one has. Analysis of a panel study has shown that causality typically works this way. In this study, discrepancies (gaps) were assessed between how respondents rated their present life on a 20-step scale and ratings of what they wanted from life (expectations, aspirations, entitlements) on the same ladder scale. Comparison over time showed a significant top-down effect but no bottom-up effect (Headey \& Veenhoven, 1989, p. 117). So it seems that contentment is largely driven by happiness. If we feel good, we infer that we have most of the things we want, and if we feel bad we start looking for what we might miss.

Though affect seems to dominate the overall appraisal of life, it does not dominate equally everywhere. Correlations between overall happiness and affect balance tend to be stronger in individualistic nations than in collectivist ones (Suh et al., 1998). Likewise, the relative weight of positive and negative affect differs somewhat across cultures. Negative affect is more strongly correlated to overall happiness in individualistic nations than in collectivist ones, while positive affect correlates more with overall happiness in nations where self-expression values are endorsed than in nations where the focus is more on survival (Kuppens et al., 2008). (Scheme 3)

\section{Question 3:}

\section{ARE CONDITIONS FOR HAPPINESS SIMILAR ACROSS CULTURES?}

Do we need the same conditions to be happy? Or can some people be happy in conditions that render other people unhappy? Below, I will consider this question on two levels: the macro level of nations and at the micro level of individuals within nations.

\subsection{Much uniformity in societal requirements for happiness}

Average happiness differs markedly across nations: the highest average on a 0 to 10 scale is currently observed in Denmark (8.4) and the lowest in Zimbabwe (3.2) ${ }^{15}$. There is a clear system in these differences. People live more happily in the most modern nations, in particular in nations characterized by economic development, freedom, rule of law, and good governance. The societal characteristics set out in Scheme 4 explain no fewer than 75 percent of the differences in average happiness in nations ${ }^{16}$. Societal progress in these matters is likely to have fostered the recent rise of happiness in modern nations (e.g., Inglehart et al., 2008).

Interestingly, the societal conditions that make people happy are not always the conditions they value. For instance, average happiness is markedly lower in nations where women are discriminated against (ChinHonFoei, 2007), but this practice is widely approved 
in most of these countries. Likewise, corruption brings down happiness even in societies where favoritism is seen as a moral obligation.

\subsection{Much uniformity in required living conditions within nations}

There are also differences in individual happiness within nations. In a happy country like Denmark, 5 percent of the people still rate 5 or lower on the $0-10$ scale, and in an unhappy country like Zimbabwe, some 13 percent score 8 or higher. Are the reasons for high and low scores similar across nations? Below, I consider some living conditions for which crossnational data are available.

\section{Freedom}

Not only is average happiness higher in free countries, but within countries individuals are also happier the more control they have over their life. This appears, among other things, in strong correlations between personal happiness and perceived freedom and control all over the world ${ }^{17}$.

\section{Social rank}

People are typically happier on the upper steps of the social ladder than at the bottom. This appears in findings on relative income position ${ }^{18}$, occupational prestige ${ }^{19}$, subjective class identification $^{20}$ and indexes of socio-economic status ${ }^{21}$. The differences tend to be bigger at the lower end of the hierarchy. Though the correlations with happiness differ in size, they are positive all over the world. This finding fits the view that we have an innate need for social respect. Like other group animals, we are hardwired to avoid a bottom position.

\section{Marriage}

Adults are typically happier when living with a spouse than when single. The difference is around half a point on scale from $0-10$ and is largely independent of income, gender, and age. Again the size of the difference varies somewhat across time and nations, but the pattern is clearly universal $^{22}$. This finding fits the view that we are social animals, hardwired to form pairs.

\section{Personality}

Cross-national research on the relationship between happiness and personality is limited as

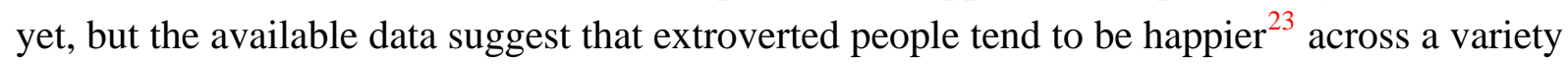
of nations (Lucas et al., 2000) and that neurotics tend to be less happy in all cultures. Once more, there is difference in the size of the effects. For instance, the effect of self-esteem appears to be stronger in individualistic cultures than in collectivist cultures (Oishi et al., 1999). Still the direction is the same everywhere.

This is not to say that all conditions for happiness are universal. One notable exception is "education." Although there is a correlation between average happiness and level of education 
in countries, the most highly educated individuals are not always happier. Correlation between happiness and education vary between -.08 and $+.27^{24}$.

\section{Question 4:}

\section{ARE THE CONSEQUENCES OF HAPPINESS SIMILAR?}

Research into happiness has focused on its determinants in the first place; however, there is also a strand of investigation into the consequences of enjoying life or not (Veenhoven, 1989a; Lyubomirsky et al., 2005). Fredrickson (2004) has summarized much of the findings in the "broaden and build theory" of positive affect. Although most of this research has been done in Western nations, the observed effects are also likely to exist in other parts of the world.

\subsection{Happiness fosters functioning}

Happiness appears to encourage engagement, while unhappiness tends to instigate withdrawal. This appears as greater engagement in activity at work ${ }^{25}$ and in leisure ${ }^{26}$. The energizing effect of happiness manifests also in social behavior: happiness predicts the formation of friendships ${ }^{27}$, entering marriage ${ }^{28}$ and participation in voluntary organizations ${ }^{29}$. There is also experimental evidence of happy moods' broadening perception and enhancing creativity $^{30}$. All this is compatible with the above-mentioned theory that happiness works as a "go signal", and that this effect seems to exists also in other higher animals. If so, the effect is likely to be universal.

\subsection{Happiness lengthens life}

Another illustrative finding is that happiness fosters physical health ${ }^{31}$ and that happiness therefore lengthens life considerably ${ }^{32}$. One of the mechanisms seems to be that happiness encourages the full functioning of mind and body and thus keeps us in shape. Another mechanism is probably that unhappiness triggers the fight or flight response, since it signals that there is something wrong. It is well known that this automatic reaction makes an organism economize on other functions, among them the immune response. In this line, Cohen (1995) has demonstrated experimentally that unhappiness makes people more susceptible to catching a common cold. The above are essentially biological reactions that are unlikely to differ much across cultures.

Possibly there are effects of happiness that do differ across cultures, but for the time being, it is the universality strikes the eye.

\section{$6 \quad$ Question 5:}

\section{DO WE ALL SEEK HAPPINESS?}

It is rather evident most humans prefer a happy life to an unhappy one. Still, this does not mean that happiness is the main driver in human motivation, nor that happiness is valued universally. 


\subsection{Happiness is a universal human striving, though not innate}

In the first lines of his famous Principles of Morals and Legislation, Jeremy Bentham (1789) stated that human behavior is governed by the pursuit of pleasure and the avoidance of pain. There is much truth in this theory of motivation, yet happiness is not the only driver of human behavior, at least not happiness in the sense of overall life-satisfaction.

Like other mammals, we are driven by different needs, such as hunger, sex, love, and curiosity, which have developed subsequently through evolution. All these needs are linked to hedonic signals, but their gratification is not only sought for the sake of pleasure. For instance, we want sex for the sex, and we do not settle for the esthetic pleasure of reading poetry instead.

Still, pleasure is a main driver of human behavior. Yet pleasure is not quite the same as life-satisfaction. Short-term pleasures can be at the cost of long-term happiness, and in such cases humans do not always look to the long term.

Our fellow animals are driven by primary motives, but in humans consciousness also gives rise to secondary motives, such as figuring out who we are and seeking an answer to questions about the meaning of life. Wentholt (1980) calls this "universal strivings", which he distinguishes from "organic needs". The pursuit of long-term happiness is one of these universal strivings. Though not "innate" as such, it is an inclination that develops in most humans as a result of their consciousness. While this inclination manifests in all cultures, it does not necessarily appear in all individuals. Happiness is typically not an issue for people who are trying to survive in the first place, and some opt to forsake happiness for ideological reasons.

\subsection{Happiness is valued in most societies, though possibly not in all}

Happiness seems to be positively valued in all nations of our time. This is at least suggested by a study among university students in 47 nations in the 1990s (Diener, 2004). These students were asked to rate the importance of several values, such as wealth, health, and love. Happiness ranked highest in the importance rating, with an average of 8 on a scale of 1 to 9 . Ratings ranged between 8.7 and 7.3, and there is thus no country in this study where happiness is deemed unimportant.

This is not to say that happiness has always been prized in all human cultures. Though all humans have a natural inclination to pursue happiness, cultures can go against that inclination just as some cultures go against the natural drive for sex. What cultures denounce happiness? Unfortunately cultural anthropology cannot tell us, since this discipline has a blind eye for happiness (Thin, 2006). Still, there are indications that in the past, miserable societies tended to glorify suffering rather than happiness ${ }^{33}$, and that collectivist cultures emphasize the well-being of groups rather than the well-being of individuals.

One can think of reasons why cultures come to depreciate happiness. When life is miserable, it may be comforting to believe that happiness is no good after all, and renouncing happiness may be functional for engaging people in common causes such as war. Next to such macro-societal functions, internal factors can be involved, such as cultural distinctions between groups in a society. This seems to have been one of the reasons for the sexual 
abstention of religious people during the Middle Ages. The campaign "against happiness" of some present-day philosophers ${ }^{34}$ could be placed in a similar vein as intellectual "distinction."

$7 \quad$ Question 6:

\section{DO WE SEEK HAPPINESS IN A SIMILAR WAY?}

To the extent that they seek happiness, do humans do this in similar ways? This question is easier put than answered, since behavior is typically guided by multiple motives that cannot be observed as such. Still we can get a clue by looking at beliefs about conditions for happiness. Do universal themes dominate these beliefs or do these lay theories of happiness tend to be culture-specific? This question can be answered in principle, but a shortage of data sets limits.

\subsection{Variation in philosophical views gives no answer}

Can we answer this question on the basis of what prominent thinkers have said on this subject in different times and cultures? We can draw on a large philosophical literature about ways to lead a happy life ${ }^{35}$, and reviews of this literature show wide differences. Yet even though philosophers differ so much, public opinion need not be equally diverse. Philosophers often seek the difference from common opinion. Moreover, philosophers often use the term happiness in a broader sense than defined here and typically write about how we should seek happiness rather than how we actually do. So, to answer this question we need to look at survey research into beliefs about happiness.

\subsection{Survey research shows much similarity}

As yet there is more comparative research on degrees of happiness around the world than on beliefs about conditions for happiness. The available research on presumed conditions for happiness is limited to present-day nation states. These data suggest that there is quite some similarity across nations.

Most of the available research findings are about perceived sources of one's own happiness $^{36}$. The bulk concerns modern Western people, who tend to believe that happiness depends on health and good relations in the first place, and less so on material affluence and social prestige.

Only a few studies have compared cultures. Chiasson \& Dubé (1997) found striking similarities in North America and Latin American countries. Likewise, Lee et al. (1999) found that students in Canada and Korea employed essentially the same ordered set of perceived sources for happiness, in spite of considerable difference in average level of happiness. A recent Gallup World Survey found that a happy family life and good health are ranked high all over the world (see Scheme 5).

Belief about conditions for happiness was addressed indirectly in Cantril's (1965) landmark study, "The Pattern of Human Concerns" in 16 nations in the early 1960s. This study involved open-ended questions about what constitutes the "best possible life" and the "worst possible life." Analysis of the responses showed much similarity; the same themes 
popped up in all countries, though not equally frequent everywhere (pp.162-167). The observed differences appeared to correspond more with the country's stage of societal development than with its ideology (p. 302). Cantril explained these observations in terms of need theory (Chapter 16).

Studies by Tsai et al. (2007) address differences in both ideal and actual affect across cultures and suggest that culture influences ideal affect more than actual affect. Still, a look at their findings shows much similarity in ideal affect, and in particular, similarly high ratings for the desirability of happiness.

\section{Question 7:}

\section{ARE WE ABOUT EQUALLY HAPPY IN ALL CULTURES?}

The last question is about degree of happiness. Are humans about equally happy in all cultures, or do they live happily in some cultures and unhappily in others?

Some variants of the comparison theory of happiness imply that humans are about equally happy in all cultures. If happiness depends on social comparison with one's compatriots, the average level will be about neutral in all societies. If happiness depends on comparison with earlier experiences over the lifetime, the average will tend to be neutral as well. Yet other variants of comparison theory imply that happiness can differ across cultures. If happiness depends on meeting local standards of the good life, happiness can be high in cultures where these standards can be easily met and low where the meeting of these standards is out of reach for most people.

Need-theory also implies that the level of happiness can differ across cultures. If happiness depends on the degree to which human needs are met, average happiness will be higher in societies that fit human nature well than in societies that do not. From a functional point of view, it is unlikely that we are equally happy irrespective of conditions. At best, evolution has resulted in a tendency to feel happy once conditions are tolerable.

The data are quite clear on this matter. There are wide differences in average happiness across nations (see Scheme 6). Average happiness ${ }^{37}$ is 8.2 in Denmark and only 3.2 in Zimbabwe. Average happiness is above neutral in the present-day world ${ }^{38}$. As we have seen in Scheme 4, most of these differences can be explained by national characteristics such as wealth, freedom, and security, which are part of "modernity."

Average happiness not only differs among contemporary cultures, but also varies over time. The level of happiness has risen in most nations over the last 30 years, but declined in some (Veenhoven \& Hagerty, 2006; Inglehart, 2008). Average happiness fell dramatically in the Russia and China following the great social changes that have taken place since the 1980s (Brockmann et al., 2008). Though people live more happily in modern society, the change to modernity tends to reduce happiness temporarily.

There are also indications that average happiness has varied considerably over human history. Our forefathers seem to have been fairly happy when living as hunter-gatherers, but less so in the agrarian phase of societal evolution. The industrial revolution brought not only more material comfort, but also an unprecedented rise in happy life years (Veenhoven, 2008). 


\subsection{Limitations}

In his book The Pattern of Human Concerns, Headley Cantril (1965, p. 315) notes that "differences between individuals and groups are often easier to detect than the similarities they obscure." An illustrative case is eating; cultural differences in eating behavior catch the eye: for example, when you find snake on your plate at a business dinner in China. Yet all humans want to eat, do eat, and need about the same nutrients. It is difficult to express this universality in numbers, since it depends rather on an interpretation of what is most essential. As such, my argument may not convince everybody.

A more tangible limitation is in the data used in this chapter. Since anthropology has failed to inform us about happiness in pre-modern societies (Thin, 2007), we must largely make do with data gathered in more or less modern societies, in particular in rich Western societies. The few studies of pre-modern societies I have mentioned (Biswas Diener, 2005; Kilpatric \& Cantril, 1960) do not cover all the questions addressed here. Furthermore, the data are not free from cultural measurement bias. For instance: Latin Americans value positive affect more and may for that reason report more positive affect than Asians do (Diener \& Oishi, 2004). Lastly, the question about variation across cultures is largely answered using data on happiness in nations.

\subsection{Why is the idea of cultural relativity so popular?}

In spite of these limitations, it is pretty clear that happiness is not only in the minds of Western people, and that there is a striking similarity in conditions for happiness across cultures. This elicits the question of why so many social scientists believe that happiness is culture-specific. One answer to that question is that theory plays them false; most social scientists have been raised with the idea that human experience is socially constructed and are trained to see human behavior as guided by malleable preferences. Another answer is a moral aversion to utilitarianism that gives rise to discounting the significance of happiness. I have discussed this question in more detail in Veenhoven (2006).

\section{CONCLUSION}

The available data suggest that all humans tend to appraise how much they like the life they live. In appraising life we draw on how well we feel in the first place, which in its turn draws on how well our universal human needs are gratified. The overall appraisal of one's life draws less on cognitive comparison with cultural standards of the good life. Consequently, conditions for happiness appear to be quite similar across the world. The consequences of enjoying life are also largely universal. There is more cultural variation in the valuation of happiness and in beliefs about conditions for happiness. The greatest variation is to be found in how happy people are. 


\section{REFERENCES}

Ball, R., \& Chernova, K. (2008). Absolute income, relative income and happiness. Social Indicators Research, 8, 497-529.

Bentham, J. (1789). Introduction to the Principles of Morals and Legislation. Original edition, London: Payne. Reprinted by Althone Press, London, 1970.

Biswas-Diener, R., Diener, E., \& Vitterso, J. (2005). Most people are pretty happy, but there is cultural variation: The Inughuit, the Amish and the Maasai. Journal of Happiness Studies, 6, 205-226.

Brockmann, H., Delhey, J., Welzel, C., \& Yuan, H. (2008). The China puzzle: falling happiness in a rising economy. Journal of Happiness Studies (in press).

Bruckner, P. (2000). L'Euphorie perpetuelle: essai sur le devoir de bonheur. Grasset, France. Cantril, H. (1965).The pattern of human concern. New Jersey: Rutgers University Press.

Chambers, J. C. (1999). Situating psychological well-being: Exploring cultural roots of its theory and research. Journal of Counseling and Development, 77, 141-152.

Chiasson, N., \& Dubé, L. (1997). La Conception du bonheur: similitudes et differences interculturelles. Revue québécoise de psychologie,18, 121-144.

ChinHonFoei, S. S. (2007).Gender equality and happiness in nations. Paper presented at Dag van de Sociologie, Tilburg, Netherlands, June 8th-2006.

Cohen, S., Doyle, W. J., Skomer, D. P., Fireman, P., Gwaltney, J. M., \& Newson, J. P. (1995). State and trait negative affect as predictors of subjective and objective symptoms of respiratory viral infections. Journal of Personality and Social Psychology, 68, 159-169.

Damasio, A. (1994). Descartes’ error. New York: Putman.

Davidson, R. J. (2004). Well-being and affective style: Neural substrates and biobehavioural correlates philosophical transactions. Biological Sciences, 359, 1395-1341.

Diener, E., Emmons, R. A., Larsen, R. J., \& Griffin, S. (1985).The satisfaction with life scale. Journal of Personality Assessment, 49, 71-75.

Diener, E. (1996). Most people are happy. Psychological science, 7, 181-185.

Diener, E., Gohm, C. L., Oishi, S., \& Suh, E. M. (2000). Similarity of the relation between marital status and subjective well-being across cultures. Journal of Cross-Cultural Psychology, 31, 419-436.

Diener, E., \& Oishi, S. (2004). Are Scandinavians happier than Asians? Issues in comparing nations on subjective well-being. Asian Economic and Political Issues, 10, 1-25.

Ekman, P. (1970). Universal facial expression of emotion. Californian Mental Health Research Digest, 8, 151-158.

Fredrickson, B. L. (2004). The Broaden-and-Build Theory of Positive Emotions. Philosophical Transactions, Biological Sciences, 359, 1367-1377.

Harter J. K., \& Arora, R. (2009). The impact of time spent working and job-fit on well-being around the world. In E. Diener, D. Kahneman, and J. F. Helliwell (Eds.), International differences in well-being. Oxford, UK: Oxford University Press. 
Headey, B., \& Veenhoven, R. (1989). Does happiness induce a rosy outlook? In R. Veenhoven (Ed.), How harmful is happiness? Consequences of enjoying life or not (pp. 106-127). Rotterdam: University Press.

Heady, B., Veenhoven, R., \& Wearing, A. (). Top-down versus bottom-up: Theories of subjective well-being. Social Indicators Research, 24, 81-100.

House, R. J., Hanges, P. J. Javadin, M., Dorfman, P. W., \& Gupta, V. (2004). Culture, leadership and organizations. The GLOBE study of 62 societies. London: Sage.

Inglehart, R., Foa, R., Peterson, C., \& Wetzel, C. (2008). Development, freedom and rising happiness: A global perspective: 1981-2007. Perspectives on Psychological Science, 3, 268-285.

Isen, A. M. Doubman, K. A., \& Nowiki, G. P. (1998). Positive affect facilitates creative problem solving. In: J. M. Jenkins, K. Oatley, \& N. L. Stein (Eds.). Human emotions: A reader (pp. 288-297). Malden, MA: Blackwell Publishers.

Kilpatrick, F. P., Cantril, H. (1960). Self-anchoring scaling: A measure of individuals' unique reality worlds. Journal of Individual Psychology, 16, 158-173.

Kuppens, P., Realo, A., \& Diener, E. (2008). The role of positive and negative emotions in life-satisfaction judgment across nations. Journal of Personality and Social Psychology, 95, 66-75.

Lee, D. Y., Park, S. H. Uhleman, M. R., \& Patsula, P. (1999). What makes you happy? A comparison of self-reported criteria between two cultures. Social Indicators Research, 50, 351-362.

Lucas, R. E., Diener, E., Grob, A., Suh, E. M., \& Shao, L. (2000). Cross-cultural evidence for the fundamental features of extraversion. Journal of Personality and Social Psychology, 79, 452-468.

Lyubomirsky, S., Diener, E., \& King, L. A. (2005). The benefits of frequent positive affect: Does happiness lead to success? Psychological Bulletin, 131, 803-855.

Maslow, A. H. (1970). Motivation and personality. New York: Harper \& Row.

Michalos, A. C. (1991). Global report on student well-being. Vol. 1: Life satisfaction and happiness. New York: Springer.

McMahon, D. M. (2008). The pursuit of happiness in history. In: M. Eid \& R. J. Larsen (Eds),The science of subjective well-being (pp. 80-93). New York: The Guilford Press.

Oishi, S. (2009). Culture and well-being: Conceptual and methodological issues. In E. Diener, D. Kahneman, \& J. F. Helliwell (Eds.), International differences in well-being. Oxford, UK: Oxford University Press.

Oishi, S., Diener, E., Lucas, R. E., \& Suh, E. (1999). Cross-cultural variation in predictors of life-satisfaction: Perspectives from needs and values. Personality and Social Psychology Bulletin, 25, 980-990.

Rayo, L., \& Becker, G. S. (2007). Evolutionary efficiency and happiness. Journal of Political Economy, vol. 115,: 302-337

Russell, J. A. (1994). Is there universal recognition of emotion from facial expression? A review of cross-cultural studies. Psychological Bulletin, 115, 102-141. 
Spogárd, R. (2005). World opinion: A happy family and good health is what matters most in life. Retrieved on June $6^{\text {th }} 2009$ from http://www.gallup-international.com/ContentFiles/millenium16.asp.

Schimmack, U., Radharkrishan, P., Oishi, S. Dzokoto, V., \& Ahadi, S. (2002). Culture, personality and subjective well-being: Integrating process model of life satisfaction. Journal of Personality and Social Psychology, 82, 582-593.

Suh, M. E., Diener, E., Oishi, S., \& Triandis, H. C. (1998). The shifting basis of life satisfaction judgments across cultures: Emotion versus norms. Journal of Personality and Social Psychology, 74, 482-493.

Thin, N. 2005. Happiness and the sad topics of anthropology. WeD Working Paper 10 ESCR. Research Group on Well-Being in Developing Countries.

Thin, N. (2008). "Realising the substance of their happiness”: How anthropology forgot about Homo gauisus. In A. Corsin Jimenez (Ed.), Culture and well-being (pp. 134-155). London: Pluto Press.

Tsai, J., Knutson., \& Fung, H. H. (2006). Cultural variation in affect valuation. Journal of Personality and Social Psychology, 90, 288-307.

Veenhoven, R. (1984). Conditions of happiness. Dordrecht, Netherlands: Reidel.

Veenhoven, R. (1989a). How harmful is happiness? Consequences of enjoying life or not. Rotterdam, Netherlands: University Press.

Veenhoven, R. (1989b). Does happiness bind? Marriage chances of the unhappy. In R. Veenhoven (Ed.), How harmful is happiness? Consequences of enjoying life or not. Rotterdam, Netherlands: University Press.

Veenhoven, R. (1991). Is happiness relative? Social Indicators Research, 24, 1-34.

Veenhoven, R. (2000). The four qualities of life: Ordering concepts and measures of the good life. Journal of Happiness Studies, 1, 1-39.

Veenhoven, R. (2005). Is life getting better? How long and happily do people live in modern society? European Psychologist (special section, "Human development and wellbeing”), 10, 330-343.

Veenhoven, R. (2006). Sociology's blind eye for happiness. Paper presented at the 16th World Congress of Sociology. Durban, South Africa. Available at: http://www2.eur.nl/fsw/research/veenhoven/Pub2000s/2006g-full.pdf . Accessed June 6th 2009.

Veenhoven, R. (2008). World Database of Happiness: Continuous register of scientific research on subjective enjoyment of life. Retrieved on June $6^{\text {th }} 2009$ from http://worlddatabaseofhappiness.eur.nl.

Veenhoven, R. (2008b). Healthy happiness: Effects of happiness on physical health and the consequences for preventive health care. Journal of Happiness Studies, 9, 449-464.

Veenhoven, R. (2008c). Comparability of happiness across nations. School of Sociology and Social Work Journal, 104, 211-234.

Veenhoven, R. (2009). How do we appraise how happy we are? In A. Dutt \& B. Radcliff (Eds.), Happiness, economics and politics. Cheltenham, UK: Edward Elgar Publishers (in press). 
Veenhoven, R., \& Hagerty, M. (2006). Rising happiness in nations, 1946-2004. A reply to Easterlin. Social Indicators Research, 79, 421-436.

Verne, P. (2008). Happiness, freedom and control. Journal of Economic behaviour and Organization 71: 146-161?

Wilson, E. G. (2008). Against happiness: In praise of melancholy. New York: Farrar, Straus \& Giroux.

Wentholt, R. (1980). Map motivatieleer. Erasmus Universiteit Rotterdam.

Wessman, A. E. (1956). A psychological inquiry into satisfaction and happiness. Unpublished doctoral dissertation. Princeton University, New Jersey.

Zajonc, R. B. (1984), On the primacy of affect. American Psychologist, 39, 117-123. 


\section{NOTES}

${ }^{1}$ This is not to say that appraisals of beauty are entirely culturally specific, since there is good evidence of universal tendencies on this matter.

${ }^{2}$ In other chapters of this book the term subjective well-being is used for this concept, while the terms happiness and life-satisfaction denote survey questions using these words. I cannot follow that terminology since this chapter draws on the World Database of Happiness, which is organized on the basis of a different idiom.

${ }^{3}$ There is some cultural variation in recognition of "fear," "anger” and "disgust” in facial expressions (see, e.g., Russell, 1994). Still, the pattern is largely universal, and recognition of "happy" emotion stands out as the most universal. Expression of emotion may be more universal than the recognition of it in other people.

${ }^{4}$ World Database of Happiness, Correlational Findings, subject section "Current Happiness” (H6.2.2.2), one study that observed a correlation of +.56.

${ }^{5}$ World Database of Happiness, Correlational Findings, subject section "Current Happiness” (H6.2.2.3), one study.

${ }^{6}$ World Database of Happiness, Correlational Findings, subject section "Reputation of Happiness” (H8.2), four studies that observed correlations between +.43 and +.64 .

${ }^{7}$ World Database of Happiness, States of Nations, Variable Happiness_DKLS_1980_2000. Average percent “don’t know” in 76 nations: 0.75; range, 0.4 to 4.5 .

${ }^{8}$ Analysis of non-response to the questions on happiness and life-satisfaction in the World Values Survey shows some variation across cultures. The percentage of “don't know" responses is slightly higher in nations where unhappiness prevails $(r=+.10)$ and also higher in collectivist cultures $(\mathrm{r}=+.21)$. Still, these are variations on an otherwise universal pattern.

${ }^{9}$ The distinction between deficiency needs and growth needs is part of Maslow's (1970) theory of human motivation.

${ }^{10}$ Rayo and Becker (2007) have a different view and argue that we are hardwired to compare and prefer the best, since this is evolutionarily advantageous. Their argument is appealing. Still, more is not always better and can even be detrimental. The tendency to compare can also be explained on the basis of innate needs that are not exclusively human, such as the need for social status and the need to use and develop one's potentials. I do buy that we tend to see things in a comparative perspective, but see that rather as a consequence of cognition than as a "need" in itself. The distinction between consequences of human consciousness and innate "needs" is further discussed in the response to Question 5.

${ }^{11}$ This analysis involved eight studies, the results of which are summarized in the World Database of Happiness, Collection of Correlational Findings, Section H6.1.2, "Current Happiness: Overall Happiness by Hedonic Level of Affect." The analysis is limited to 
studies among general population samples using comparable single, direct questions on overall happiness (type O-HL, O-SL, O-DT, O-QOL) and affect (type A-AOL).

Correlation with affect balance (type A-AB) is lower (+.50 in 70 studies), but in this case the correlation is depressed by the timeframe of the questions, which is typically 'the last few weeks'.

12 This analysis involved seven studies, the results of which are summarized in the World Database of Happiness, Collection of Correlational Findings, Section H6.1.3, "Current Happiness: Overall Happiness by Contentment.” The analysis is limited to studies among general population samples using comparable single, direct questions on overall happiness (type O-HL, O-SL, O-DT) and contentment (type C-BW).

${ }^{13}$ This analysis involved three studies, the results of which are summarized in the World Database of Happiness, Collection of Correlational Findings, Section H6.23 "Current Happiness: Hedonic Level of Affect by Contentment.” The analysis is limited to studies among general population samples. Hedonic level was measured using affect balance Scales (type A-AB) and contentment using the Cantril Ladder (type C-BW) and questions about perceived realization of wants (type C-RW).

${ }^{14}$ Wessman wrongly interpreted Table 44 as showing that unfulfilled aspirations go with unhappiness.

${ }^{15}$ World Database of Happiness, Happiness in Nations, Rank Report 2009-1.

${ }^{16}$ Similar results are obtained when average happiness is measured using an affect balance scale instead of a single direct question on satisfaction with life-as-a-whole (Variable in data file "states of Nations": HappinessYesterdaysAffect3_2006). ${ }^{40}$

${ }^{17}$ World Database of Happiness, Correlational Findings, subject section "Personality, Inner Locus of Control (P4.58). For a recent cross-national study, see Verne (2008).

${ }^{18}$ World Database of Happiness, Correlational Findings, subject section "Current Income" (1.2). For a recent cross-national comparison, see Ball and Chernova (2008).

${ }^{19}$ World Database of Happiness, Correlational Findings, subject section "Current Occupational Level” (O1.3.1).

${ }^{20}$ World Database of Happiness, Correlational Findings, subject section "Subjective Social Rank” (S9.2.2).

${ }^{21}$ World Database of Happiness, Correlational Findings, subject section "Objective Social Status” (S9.2.1).

${ }^{22}$ World Database of Happiness, Correlational Findings, subject “Marital Status” (M2.1). See also Diener et al. (2000).

${ }^{23}$ Schimmack et al. (2002) found that the link between extroversion and hedonic level of affect is more universal than the link between extroversion and overall happiness and suggest that the influence of personality on the emotional component of happiness is pan- 
cultural, whereas the influence of personality on the cognitive component of happiness is more moderated by culture.

${ }^{24}$ World Database of Happiness, States of Nations, variable r_LS_Education_1990.

${ }^{25}$ World Database of Happiness, Correlational Findings, subject “Later Work Performance"(code W6.1.4).

${ }^{26}$ World Database of Happiness, Correlational Findings, subject "Later Leisure”(code L3.1.4).

${ }^{27}$ World Database of Happiness, Correlational Findings, subject “Later Friendships” (code F6.1.4).

${ }^{28}$ World Database of Happiness, Correlational Findings, subject "Later Marriage” (code M1.4). See also Veenhoven (1989b).

${ }^{29}$ World Database of Happiness, Correlational Findings, subject "Later Organizational Participation”(code S7.1.4).

${ }^{30}$ See, e.g., Isen (1998).

${ }^{31}$ World Database of Happiness, Correlational Findings, subject "Later Physical Health" (code P6.1.4).

${ }^{32}$ World Database of happiness, Correlational Findings, subject "Longevity” (code P6.1.4.1). See also Veenhoven (2008b).

33 This appears, for instance, in the history of philosophical thought. Happiness was a common theme in the prosperous Antique city societies, but disappeared in the dark Middle Ages and popped up again in the seventeenth century, together with a rise in quality of life of the new middle class.

${ }^{34}$ See, e.g., Bruckner (2000), and Wilson (2008).

${ }^{35}$ World Database of Happiness, Bibliography of Happiness, subject "Perceived Sources of Happiness” (code 15a2). For a recent review, see MacMahon (2008).

${ }^{36}$ World Database of Happiness, Bibliography of Happiness, subject "Perceived Sources of One’s Own Happiness (code 15c1).

${ }^{37}$ Overall happiness measured with a survey question on life-satisfaction. Average contentment, as measured with Cantril's Best-Worst Possible Life question, is closer to neutral, which fits the prediction of comparison theory.

${ }^{38}$ World Database of Happiness, Happiness in Nations, Rank Report 2009-1. See also Diener, 1996. 
${ }^{40}$ The data file "States of Nations" is available on request. The variables used here are:

HappinessBWLS11_2006, RGDP_2000_2004, FreeEconIndex2_2002,

DemocracyIndex2_2004, PeaceIndex_2007, Corruption3_2006, RuleLaw_2006,

IncomeInequality1_2005, GenderEqualIndex2_2005, EduEnrolGross_2000_04, IQ_2006.

These variables are described on the website:

http://www.worlddatabaseofhappiness.eur.nl/statnat/statnat_fp.htm 


\section{Scheme 1}

“Don't Know” response to survey questions about happiness.

\begin{tabular}{|l|c|}
\hline USA & $0.19 \%$ \\
\hline Zimbabwe & $0.26 \%$ \\
\hline China & $0.49 \%$ \\
\hline France & $0.65 \%$ \\
\hline Russia & $1.42 \%$ \\
\hline India & $2.69 \%$ \\
\hline Average in 78 nations & $\mathbf{0 . 7 5 \%}$ \\
\hline
\end{tabular}

Source: World Values Surveys, life-satisfaction item, average waves 1 to 4 
Scheme 2

Concepts of happiness: Overall happiness and components

global assessment

sub-totals:

information basis

\section{OVERALL HAPPINESS}

Satisfaction with one's life-as-whole

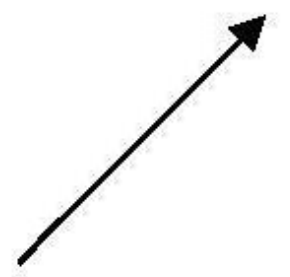

Hedonic level of affect Balance of pleasant and unpleasant affect

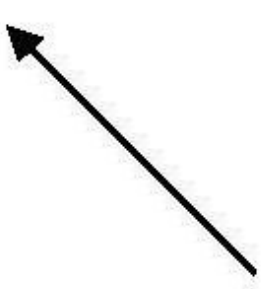

Contentment

Perceived realization of wants

Cognitive comparison

Source: Veenhoven 1984 


\section{Scheme 3}

Theories of happiness: significance of two causal paths

global assessment

sub-assessment:

Information basis

underlying process

substrate

\section{OVERALL HAPPINESS}

Satisfaction with one's life-as-whole

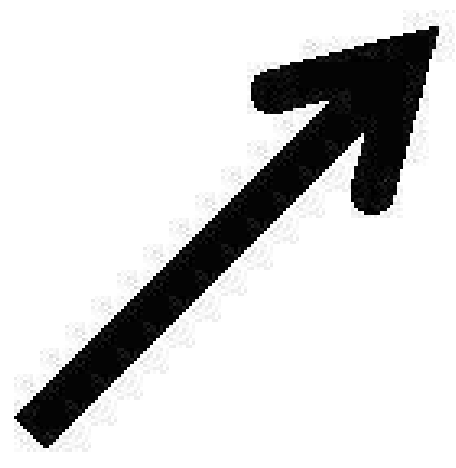

Hedonic level of affect

Balance of pleasant and unpleasant affect

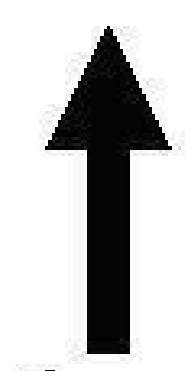

Affective experience

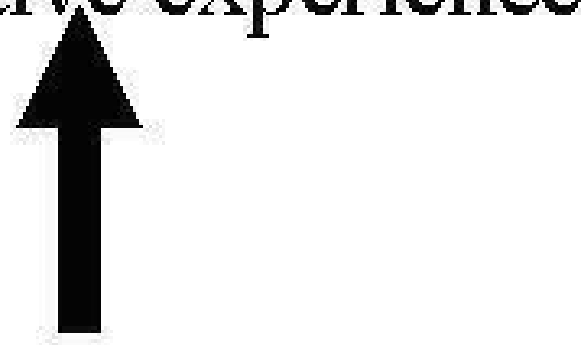

Need gratification

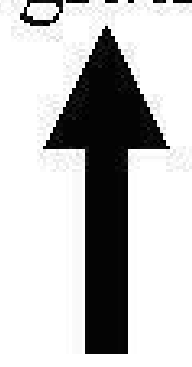

Human nature

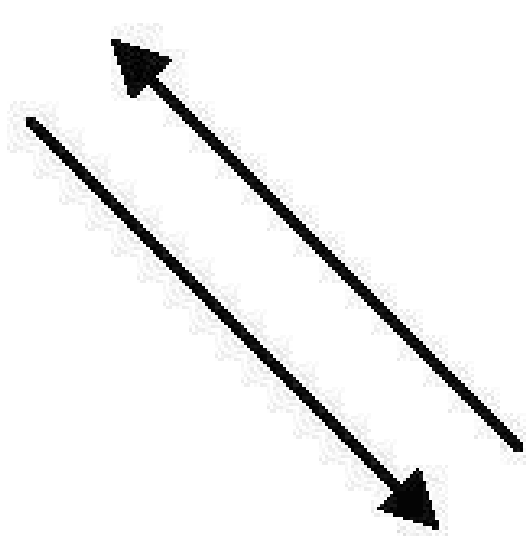

Contentment

Perceived realization of wants

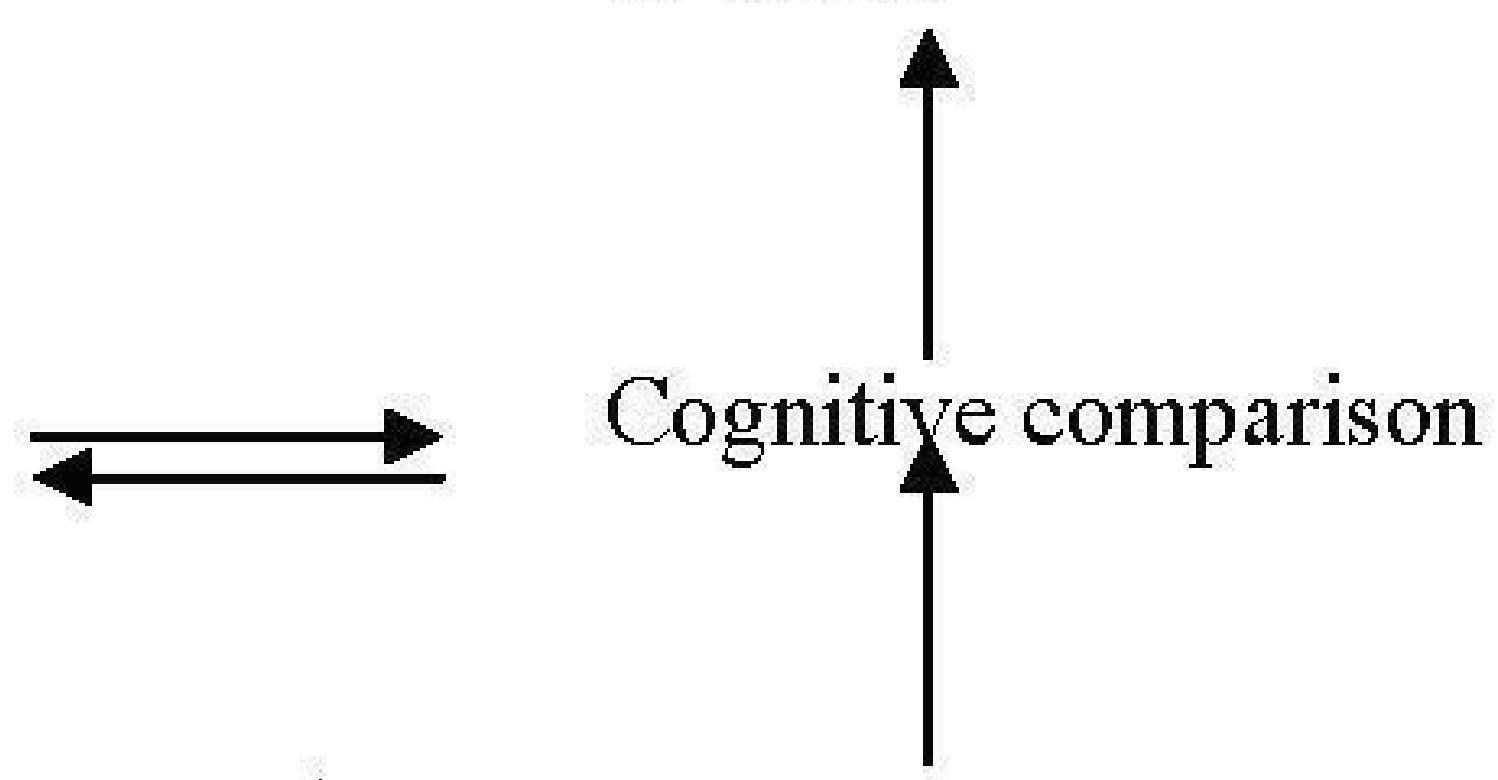

Standard setting

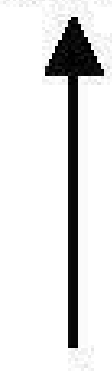

Culture 


\section{Scheme 4}

Average happiness by societal characteristics in 136 nations 2006

Zero order wealth controlled

Wealth

- Income $\mathrm{p} / \mathrm{c}$

$+.79$

$--$

Freedom

- economic freedom

$+.62$

$+.11$

- political freedom

$+.50$

$+.07$

Peace

$+.39$

$+.15$

Justice

- corruption

$-.77$

$-.14$

- rule of law

$+.70$

$+.06$

Equality

- income equality

$+.27$

$-.33$

- gender equality

$+.67$

$+.19$

Education

- school enrolment

$+.57$

$+.12$

- intelligence

$+.63$

$+.21$

Source: World Database of Happiness (Veenhoven 2008, datafile States of Nations ) ${ }^{40}$ 


\section{Scheme 5}

\section{Perceived sources of happiness}

Responses to question: "What matters most in life? Tell me only the two things that matter the very most in life.

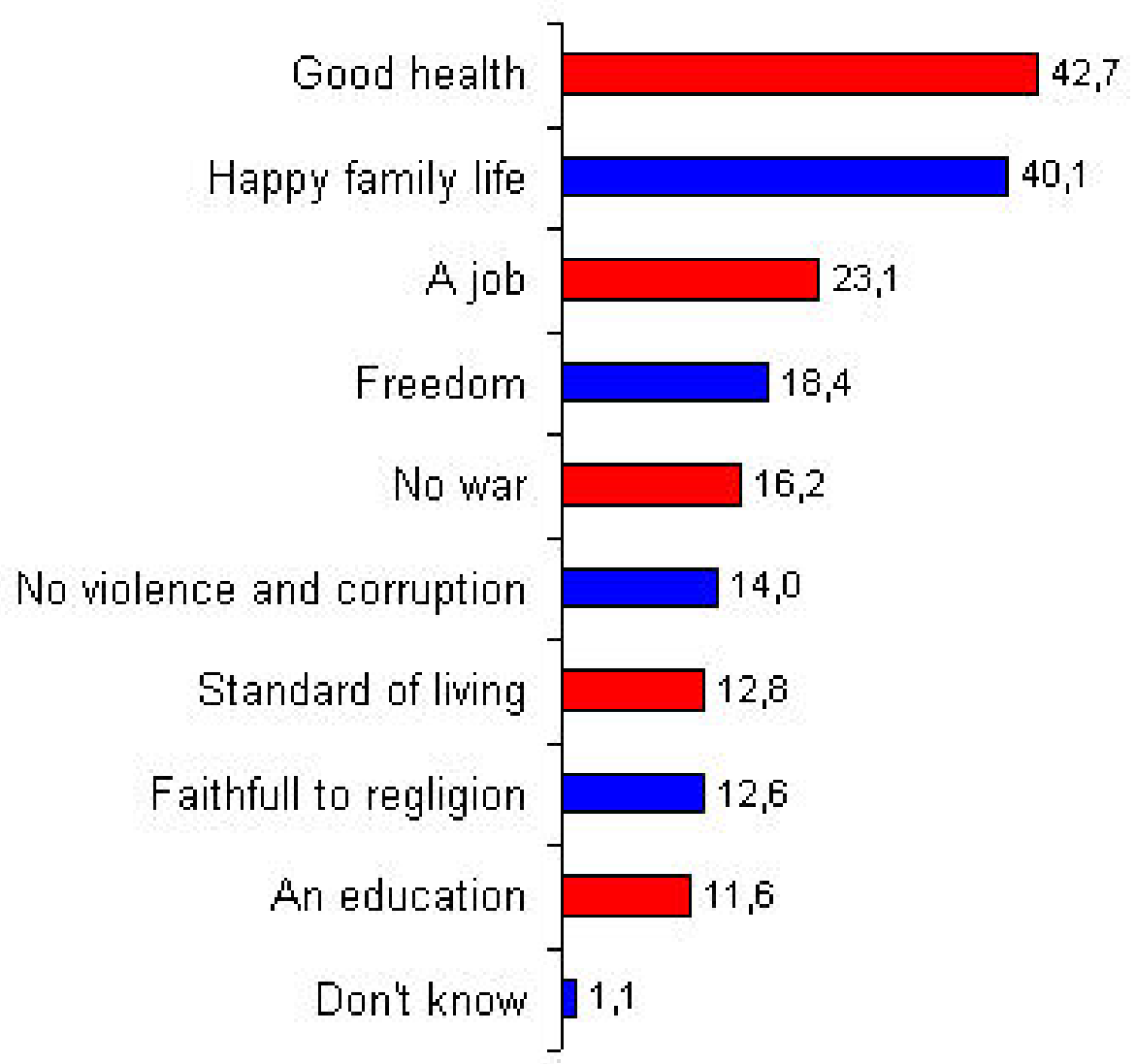

Source: Gallup Millennium World Survey (Spogárd 2005) 


\section{Scheme 6}

Happiness in nations around 2000, averages on scale 0-10.

\begin{tabular}{|l|c|}
\hline Denmark & 8.2 \\
\hline Sweden & 7.7 \\
\hline USA & 7.4 \\
\hline Germany & 7.2 \\
\hline France & 6.5 \\
\hline Philippines & 6.4 \\
\hline Japan & 6.2 \\
\hline Turkey & 5.2 \\
\hline Russia & 6.5 \\
\hline Zimbabwe & 4.4 \\
\hline Average in 86 nations & \\
\hline
\end{tabular}

Source: World Database of Happiness, Happiness in Nations (Veenhoven, 2008). 